\title{
Self-reflection, epistemological beliefs, and conceptual gains*
}

\author{
David B. May, Physics Education Research Group, The Ohio State University \\ Eugenia Etkina, Rutgers, the State Univ. of New Jersey
}

\begin{abstract}
Twelve honors introductory physics students were chosen for having exceptionally high or low gains on standard conceptual surveys. Their weekly written journals were analyzed for the quality of reflection on what and how they learn. The high-gain students tended to write more than the low-gain students and showed reflection that was more epistemologically sound.
\end{abstract}

\section{Introduction}

There is growing recognition in the learning research of the important role played by students' beliefs about the nature of knowledge and learning. The particular constructs studied include beliefs about how knowledge is constructed and evaluated, the source of knowledge, and the nature of learning, collectively known as epistemological beliefs. ${ }^{1}$ A related factor is the ability of students to reflect on how they learn.

Although appropriate epistemological beliefs and self-reflection skills may be important instructional goals in their own right, they may also be related to more commonly-measured forms of academic performance, such as conceptual understanding or problem-solving ability. ${ }^{2}$

We studied weekly journals written by students to begin answering three questions related to epistemological beliefs and selfreflection:

1. How articulate are students in describing how they learn?

2. How consistently do students report particular ways of learning?

3. Are there correlations between these patterns (if they exist) and standard measures of conceptual understanding?

\section{Methodology}

The course

The student sample was chosen from the physics sequence for participants in the Freshman Engineering Honors program at The Ohio State University. The first 10week quarter covered introductory mechanics; the second covered electricity and magnetism. Two instructors each taught one section of the course in the first quarter, and two different instructors each taught a section in the second quarter. Approximately two hundred students were enrolled in the sequence.

Research-based, active-learning strategies were employed extensively in all sections, and included interactive "lectures," cooperative group problem-solving, and other non-traditional innovations. ${ }^{3}$ These methods had been used in this course for several years by one of the instructors. Each week students were to attend three one-hour lectures, two one-hour recitations, and one two-hour laboratory.

In addition, the course embodied a learning environment ${ }^{4}$ that mirrored the investigative character of science. An idealized scientific method permeated the course, which cycled through the process of observation, creating qualitative explanations, developing mathematical explanations, designing experiments to test and find the limitations of these explanations, and applying concepts and skills to solve problems. In this way, the course structure emphasized the process of science and the proper justification for scientific knowledge.

Each week students reflected on what and how they learned by writing Weekly Reports, ${ }^{5}$ structured journals in which students are asked four open-ended questions:

1. What did you learn in lab this week? How did you learn it?

2. What did you learn in lecture and recitation this week? How did you learn it?

3. What questions remained unclear? 
4. If you were the professor, what questions would you ask to determine if your students understood the material?

Students responded via the web; responses were typically one page long, though many were longer. Half of the reports were graded each week.

\section{Summative assessment}

The Force Concept Inventory ${ }^{6}$ (FCI) was given at the beginning and end of the first quarter, and the Mechanics Baseline Test $^{7}$ (MBT) was given at the end. The Conceptual Survey of Electricity and Magnetism $^{8}$ (CSEM) was given in the second quarter, before and after instruction.

\section{The sample}

From the half of the class that had the lowest FCI pretest scores (that is, those who had the largest chance for gain), we chose the students with the lowest and the highest FCI gains (about ten of each). We then removed a few students from each group who did not also have corresponding low (or high) MBT scores and CSEM gains. The sample ultimately consisted of six "low gainers" and six "high gainers."

The normalized FCI and CSEM gains for the students are listed below.

\begin{tabular}{|c|c|c|c|c|c|c|c|}
\hline $\begin{array}{c}\text { Low } \\
\text { group }\end{array}$ & FCI & .12 & .18 & .19 & .20 & .33 & .35 \\
\hline \multirow{2}{*}{$\begin{array}{c}\text { High } \\
\text { group }\end{array}$} & FCI & .06 & .05 & .31 & .09 & .25 & .22 \\
\cline { 2 - 7 } & CSEM & .72 & .60 & .87 & .87 & .88 & .93 \\
\hline
\end{tabular}

\section{Weekly Reports}

We observed students' reflective skills and epistemological views in the text of their reports. The students in our sample each completed 13-19 reports during the 20week period.

One of us (EE) helped grade the firstquarter reports, and was familiar with the kinds of responses students wrote. We both read many reports (of students not in our sample) and developed an initial coding scheme. The scheme was finalized after reading the reports of our sample students.
Fourteen codes were developed and put into three categories. We coded indications of what the students said they learned, how they said they learned, and inferences we could make about other epistemological views. Because the coding scheme itself is a product of our research, it is described in the next section.

To measure how articulate each student was about how they learned, total numbers of codes were calculated. Information about each student's epistemological preferences was determined by normalizing the number of indications for each code by dividing by the total number of code indications for that student. This method controls for how much a student writes about her learning.

\section{Results}

The Coding Scheme

What they say they learned:

1. Formula - equations or other mathematical statements without elaboration on their underlying meaning

2. Vocabulary - definitions or other physics language conventions

3. Concept - qualitative descriptions or mentions of concepts, ideas, relationships

4. Skill - laboratory design skills, measurement skills, or problem-solving methods and skills

How they say they learned:

5. Observed phenomenon - pure observation

6. Constructed concept from observation learned a concept simply by observing a phenomenon or demonstration

7. Reasoned/derived in lecture - followed the reasoning process by which the large class came to a concept or formula, by using prior knowledge and experience, logic, mathematics, and/or analogies

8. Reasoned/derived in lab - actively reasoned by oneself or in a small group to come to a concept or formula

9. Learned by doing - learned a concept, definition, or formula by using it, or 
learned a skill or process by performing or practicing it

10. Authority - told or convinced by instructor, friend, textbook, or other authority figure

11. Predicted/tested - predicted the outcome of an experiment and then conducted or observed the experiment

12. Predicted/tested/interpreted - conducted an experiment to test an idea and interpreted the results of that test

Inferences about their views:

13. Applicability of knowledge - belief that physical laws or concepts can and should be applied to new problems or to real life situations

14. Concern for coherence - belief that physical laws and concepts fit together coherently, or at least should agree with each other and with common sense

\section{How articulate are they?}

Total numbers of codes attributed to the reports of each student (over the 20-week period) are listed below:

\begin{tabular}{|l|l|l|l|l|l|l|}
\hline Low group & 43 & 94 & 94 & 119 & 169 & 216 \\
\hline
\end{tabular}

\begin{tabular}{|c|c|c|c|c|c|c|}
\hline High group & 134 & 145 & 200 & 232 & 236 & 239 \\
\hline
\end{tabular}

The high gainers clearly write (on average) more about what and how they learned than the low gainers. However, how much they write about their learning is not the whole story; what they write is just as important, as closer examination reveals.

The verbose low gainer (with 216 code indications) frequently focused on authority as a source of knowledge. In fact, this student's weekly reports were coded for Authority more than twice as much as the reports of any high-gain student. For example, one week this student wrote, "The best way for me to understand ... problems was to see [the professor] working on them."

Likewise, the high gainers who wrote relatively little about how they learned (with 134 and 145 code indications) had a particular focus. They concentrated on their personal role in constructing knowledge. As one of them wrote, "We learned this by trying to forget everything we knew before we came into class, and start with the basic building blocks."

\section{Epistemological preferences}

Although each student was somewhat consistent in what they wrote, each showed a number of different indications. The average normalized number of indications for each code for the two groups is shown in Figure 1.

In terms of what the students say they learned, both groups frequently mentioned concepts and skills, hardly ever mentioning physics vocabulary. However, the low-gain students mentioned equations and formulas much more often than the high gainers.

How they say they learned also shows a few important differences. The results for codes 7 and 9 show that high gainers are much more focused on reasoning as a way of knowing than low gainers, who emphasize learning by doing much more often than the high gainers. Low gainers as a whole (not just the verbose student mentioned above) have a stronger focus on authority than high-gain students.

Predicting, testing, and interpreting test results were emphasized in the course. The related codes (11 and 12) did not appear particularly often, but still indicate an important difference between the groups. High gainers hardly ever mentioned predicting and testing without also describing interpretation of the results. On the other hand, those low gainers who mentioned predicting and testing mentioned interpretation infrequently.

Inferences made about other views showed a large difference only in code 14, Concern for coherence. The high-gain students tried to connect what they were learning to their prior knowledge of physics or the natural world much more often.

\section{Conclusions}

Our results suggest the possibility of a correlation between students' conceptual 
gains and their ability to reflect on their learning. Most students in our sample with low conceptual gains did not write much about how they learned, compared with the high gainers.

Results from specific codes suggest another possible correlation, between conceptual gains and epistemological views. Low conceptual gainers were more likely than others to mention learning activities that are epistemologically less desirable: learning formulas without heeding their conceptual implications, learning from authority, and predicting and testing without interpretation. High gainers, however, more frequently referred to reasoning and

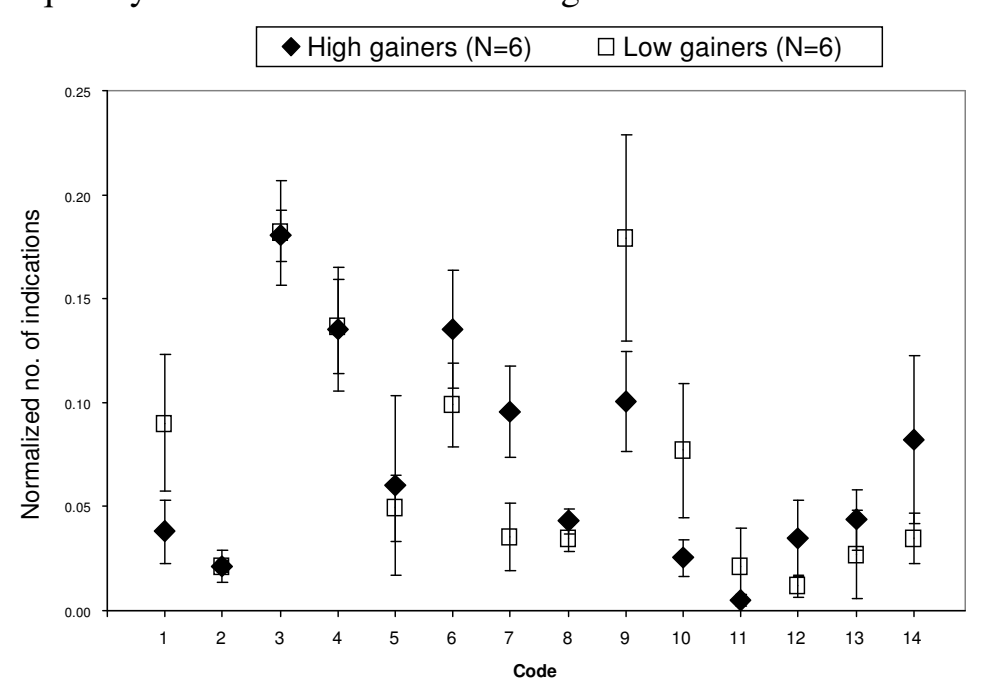

interpretation, and showed more concern for the coherence of knowledge than their counterparts.

More extensive research is needed to verify these possible correlations. However, the possibility of such connections implies that "good" students have knowledge that is appropriate epistemologically as well as conceptually, and that they are better at reflecting on what they learn and how they learn it.

*This work is supported in part by NSF grant \#GER-9553460.

Figure 1. Average normalized number of indications for each code, for high gainers and low gainers. Error bars are one standard deviation in length.

\footnotetext{
${ }^{1}$ B. Hofer, "Personal epistemology research: implications for learning and instruction," AERA meeting (2001).

${ }^{2}$ See Ref. 3 in A. Elby, "Helping physics students learn how to learn," Am. J. Phys. 69 (7), Supplement 1, S54-S64 (2001).

${ }^{3}$ A. Van Heuvelen and K. Andre, "Calculusbased physics and the engineering ABET 2000 criteria," APS Forum on Education newsletter, Spring/Summer 2000, 5-6.

${ }^{4}$ This learning system is described in E. Etkina, "Can we use the processes of physics to guide physics instruction?" published online at
}

\author{
What they learned: \\ 1. Formula \\ 2. Vocabulary \\ 3. Concept \\ 4. Skill \\ How they learned: \\ 5. Observed phenomenon \\ 6. Constructed concept from \\ observations \\ 7. Reasoned/derived in lecture \\ 8. Reasoned/derived in lab \\ 9. Learned by doing \\ 10. Authority \\ 11. Predict/test \\ 12. Predict/test/interpret \\ Inferences: \\ 13. Applicability of knowledge \\ 14. Concern for coherence
}

http://www.gse.rutgers.edu/people/ee.htm (2001).

${ }^{5}$ E. Etkina, "Weekly Reports: A Two-Way Feedback Tool", Sci. Educ., 84, 594-605 (2000).

${ }^{6}$ D. Hestenes, M. Wells, and G. Swackhamer, "Force Concept Inventory," Phys. Teach., 30, 141-158 (1992).

${ }^{7}$ D. Hestenes and M. Wells, "A Mechanics Baseline Test," Phys. Teach., 30, 159-166 (1992).

${ }^{8}$ D. Maloney, T. O'Kuma, C. Hieggelke, A. Van Heuvelen, "Surveying students' conceptual knowledge of electricity and magnetism," Am. J. Phys. 69 (7), Supplement 1, S12-S23 (2001). 